\title{
Global surface temperature signals in pine ring-width chronologies from southern monsoon Asia
}

\author{
B. M. Buckley, ${ }^{1}$ B. I. Cook, ${ }^{2}$ A. Bhattacharyya, ${ }^{3}$ D. Dukpa, ${ }^{4}$ and V. Chaudhary ${ }^{5}$ \\ Received 7 June 2005; revised 7 September 2005; accepted 13 September 2005; published 19 October 2005.
}

[1] We analyze Pinus ring width chronologies from three locations across monsoon Asia (Bhutan, India, and Thailand) where climate is dominated by the southwest monsoon in the boreal summer. We compare these records to global surface temperatures for the past 150 years, shifting the correlations through three seasonal averages: two seasons preceding the monsoon (Dec-Feb and MarMay), and the monsoon season itself (Jun-Sep). Clear patterns emerge for each of the chronologies that highlight links to areas of known influence on the Asian monsoon: the Indian Ocean, the tropical eastern Pacific Ocean, and the high-latitude Asian landmass. The Thai and Indian chronologies are from the same species (P. merkusii), and show a strong correlation with tropical Indian and Pacific Ocean bands. The Bhutan chronology (P. Wallichiana) is most strongly linked to climate over the north Pacific and Asian landmass. All of these correlations are strongest in seasons preceding the summer monsoon. Citation: Buckley, B. M., B. I. Cook, A. Bhattacharyya, D. Dukpa, and V. Chaudhary (2005), Global surface temperature signals in pine ring-width chronologies from southern monsoon Asia, Geophys. Res. Lett., 32, L20704, doi:10.1029/2005GL023745.

\section{Introduction}

[2] Variability in surface temperatures of the global ocean and over the high-latitude Asian land mass can influence the timing and intensity of the Asian monsoon [e.g., Dash et al., 2005]. There is much recent interest in the Asian monsoon, a highly complex component of the climate system that impacts a vast area, and nearly half the world's population. The monsoon affects regional climate variability through modulation of the coupled atmosphere-ocean system and interaction with meso-scale meteorological phenomena [Meehl and Arblaster, 2003]. Changes in the monsoon may contribute to rainfall anomalies that result in catastrophic droughts or floods in less-developed, largely agrarian parts of Asia. Therefore, the ability to accurately forecast the various regional expressions of the monsoon is of great significance, but requires the development of mechanistic forecast models with the necessary coupled ocean-atmosphere processes included. Expanding

\footnotetext{
${ }^{1}$ Tree Ring Laboratory, Lamont-Doherty Earth Observatory, Palisades, New York, USA.

${ }^{2}$ Department of Environmental Science, University of Virginia, Charlottesville, Virginia, USA.

${ }^{3}$ Birbal Sahni Institute of Palaeobotany, Lucknow, India.

${ }^{4}$ Tree-Ring Lab, RNR-RC, Jakar, Bhutan.

${ }^{5}$ Seismology Division, Department of Science and Technology, Technology Bhavan, New Delhi, India.
}

Copyright 2005 by the American Geophysical Union. 0094-8276/05/2005GL023745 the instrumental record with climate proxies and using these proxies to analyze spatio-temporal characteristics of the monsoon is a logical progression toward the goal of understanding monsoon climate dynamics.

[3] There is a decided lack of high resolution, long-term proxy climate information from the terrestrial tropics and subtropics. In tropical and subtropical Asia only a handful of published high-resolution climate proxies exceed 150 years in length, including ice core records [e.g., Thompson, 2001], coral records [e.g., Urban et al., 2000], and tree-ring chronologies [e.g., Borgaonkar et al., 1999; Buckley et al., 1995; D’Arrigo et al., 1994; Pumijumnong et al., 1995; Yadav et al., 1997]. Tree ring records from the Asian tropics are spatially and temporally limited due to difficulties encountered when working with tropical species [e.g., Worbes, 1995; Jacoby, 1989]. The chronologies in this paper represent the few records available from a single genus to compare across this region.

\section{Materials and Methods}

[4] We highlight the relationship between three Pinus ring-width chronologies from Bhutan, India and Thailand, respectively, with global surface temperatures extracted from the Jones et al. [2001] variance-adjusted monthly surface temperature series. These data are from corrected observations in the form of a $5^{\circ} \times 5^{\circ}$ global grid, and are not an interpolated data set. We used only grid cells with at least 50 years of data, and compared them with the tree ring indices using the Pearson correlation statistic for a point-bypoint regression between monthly values of temperature and annual growth.

[5] The tree ring chronologies (Figure 1 and Table 1) are shown for the common period 1870 to 2000, the portion of each where the Expressed Population Strength (EPS) statistic is greater than 0.85 . While there is no level of statistical significance for EPS, it is generally accepted that values above 0.85 denote sufficient strength of signal for use in paleoclimate reconstruction [Wigley et al., 1984]. The chronologies were developed using established methods for sampling, sample preparation and crossdating [e.g., Stokes and Smiley, 1968; Fritts, 1976]. The ring-width series were standardized using a two-step procedure designed to reduce potential bias and the effects of variance instability through time [see Cook and Peters, 1997]. We applied a fixed 150-year spline to each raw series and removed this trend by subtraction, rather than division, to avoid potential bias as demonstrated by Eriksson [1989]. Autoregressive modeling was applied to each series and the biweight robust mean was calculated to reduce the influence of outliers. Finally, the variance was temporally 


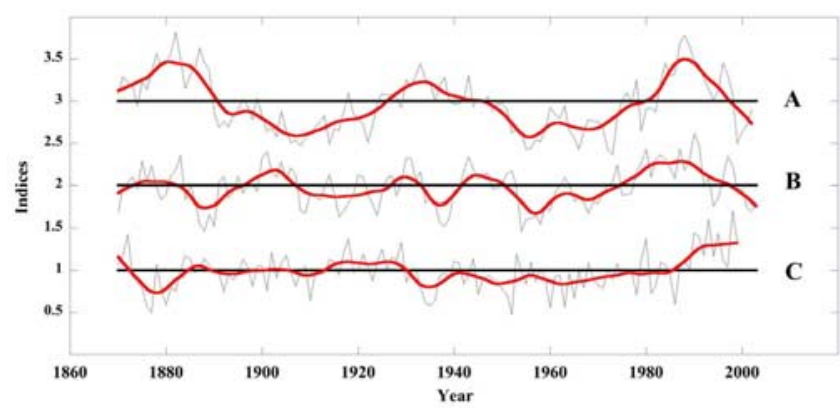

Figure 1. Chronology index plots for BLP from (a) Bhutan, (b) MHP from India and (c) SLM from Thailand.

stabilized using techniques from Osborn et al. [1997] to reduce the effects of changing sample size. This process removes the potential bias of changing variance that is not climatically driven.

\section{Results}

[6] Correlation fields shown in Figure 2 are from the region $70.0^{\circ} \mathrm{S}$ to $70.0^{\circ} \mathrm{N}$ latitude and completely encircling the globe. The three columns show correlations with Bhutan (left), India (center) and Thailand (right). Progressive seasons are shown in the rows from top; Dec-Feb (DJF) middle; Mar-May (MAM) and bottom; Jun-Sep (JJAS). Only correlations exceeding the $95 \%$ confidence limits are shown. The correlation fields encompass the three primary regions of monsoon influence described by Meehl and Arblaster [2003] (i.e., Indian Ocean SST; Tropical Pacific SST; and Asian land temperature). The most striking correlations are from the Thai and Indian P. merkusii, where a strong positive correlation is indicated over large areas of the tropical Pacific and Indian Oceans, strongest in months preceding the monsoon. The $P$. wallichiana chronology from Bhutan, while indicating some strength of signal in the Indian Ocean, does not exhibit the same strong correlation with the eastern tropical Pacific. Instead, the North Pacific signal dominates, particularly for MAM before the monsoon. Strong positive correlations are shown with SST in the Gulf of Alaska and with surface temperature for adjacent land areas. Significant negative correlations with north Pacific SST, and positive correlations with highlatitude Asian land temperature are also shown.

\subsection{Tropical Indian Ocean}

[7] The main source region for moisture entering South and Southeast Asia during the summer monsoon, in the form of latent heat flux (LHF), is from the tropical Indian Ocean and the Arabian Sea [Mohanty et al., 1996]. Studies have linked the strength of the monsoon to SST in this region [e.g., Gautier et al., 1998; Rao and Goswamy, 1988], particularly during months preceding the monsoon. The positive correlations with SST over this region likely reflect the importance of LHF preceding the monsoon in these mountain regions.

\subsection{Tropical Eastern Pacific/ENSO}

[8] The strongest correlations for the Thai and Indian pines are with the eastern equatorial Pacific Ocean from Indonesia to the west coast of South America, the primary area of ENSO activity. Indeed, the pattern of SST for ENSO is remarkably like the correlation pattern shown in Figure 2 for the Indian and Thai pines. This pattern of anomalously warm SST for the eastern tropical Pacific results in a reduction of rainfall over parts of India and north Thailand. Buckley et al. [1995] show that P. merkusii growth at SLM is inversely correlated with rainfall during the peak monsoon month of Sept., but directly correlated with rainfall for transitional seasons, from wet to dry (OctNov) and dry to wet (Mar-Apr).

[9] The lack of direct dependence on rainfall during peak monsoon likely reflects $P$. merkusii's deep taproot that suffers from excess moisture (Vinai Sirikul, unpublished data). However, the early arrival or late departure of moisture prolongs the monsoon rather than increasing its intensity during peak months, particularly at upper elevations. Recently increasing growth at SLM (Figure 1) corresponds to decreasing September rainfall across north Thailand [Komonjinda, 2003], consistent with the findings of Singhrattna et al. [2005a] for central Thailand. At the same time transitional season rainfall (Mar-Apr) has been increasing [Komonjinda, 2003].

[10] The correlation analyses of Buckley et al. [1995] and D'Arrigo et al. [1997] were based on the nearest meteorological stations from Phetchabun and Phitsanulok, both below 400 meters. In contrast the pines at SLM are from 1,500 meters in the forested mountains. Komonjinda [2003] showed the disparity between temperature, rainfall and relative humidity along a three-station transect in north Thailand ranging from 400 to 1,600 meters on the south flank of Doi Chiangdao. Rainfall at the highest station was dramatically higher than at the lowest, and often occurred during periods of drought below 800 meters. D'Arrigo et al. [1997] show significant correlation for SLM with gridded temperature across the region, which was interpreted as an indication of synoptic-scale forcing related to the strength of the monsoon that was not necessarily reflected by the local station data.

\subsection{High Latitude Land Mass}

[11] Studies have shown rather complicated links between snow depth and land temperature over Eurasia and the strength of monsoon circulation over India [e.g., Hahn and Shukla, 1976; Dickson, 1984; Sankar-Rao et al., 1996; Dash et al., 2005]. The relationship is in the form of an inverse correlation between Eurasian snow depth and Indian summer

Table 1. Details of Pine Chronologies From Bhutan, India and Thailand: BLP = Burning Lake Pinus; MHP = Mishmi Hills Pinus; SLM = Salaeng Luang Merkusii

\begin{tabular}{llllrr}
\hline Site ID & Location & Species & Lat./Long. & Elev., $\mathrm{m}$ & Timespan \\
\hline BLP & Bhutan & P. wallichiana & $27^{\circ} 30^{\prime} \mathrm{N} / 90^{\circ} 47^{\prime} \mathrm{E}$ & 2500 & $1720-2002$ \\
MHP & India & P. merkusii & $28^{\circ} 09^{\prime} \mathrm{N} / 96^{\circ} 05^{\prime} \mathrm{E}$ & 2500 & $1804-1999$ \\
SLM & Thailand & P. merkusii & $16^{\circ} 43^{\prime} \mathrm{N} / 100^{\circ} 54^{\prime} \mathrm{E}$ & 1500 & $1754-2001$ \\
\hline
\end{tabular}


Bhutan
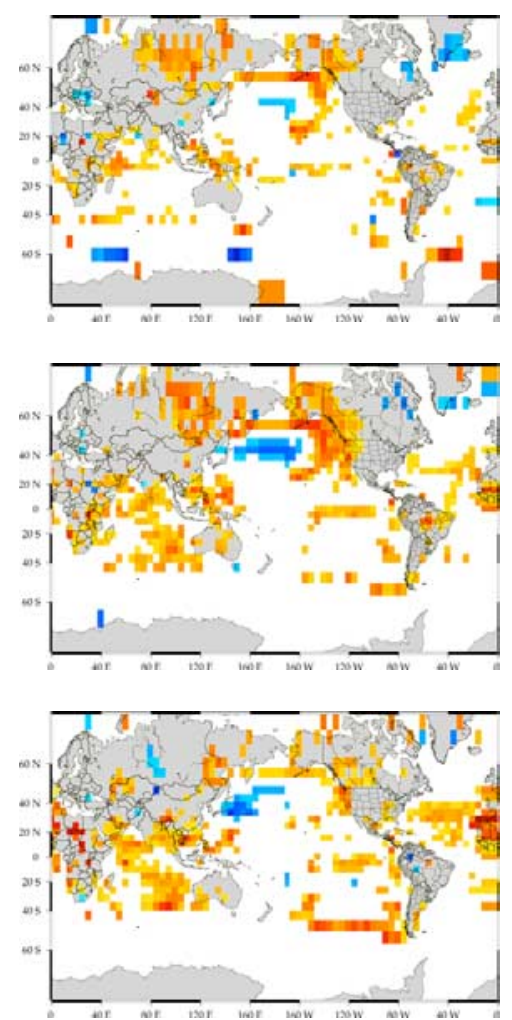

India
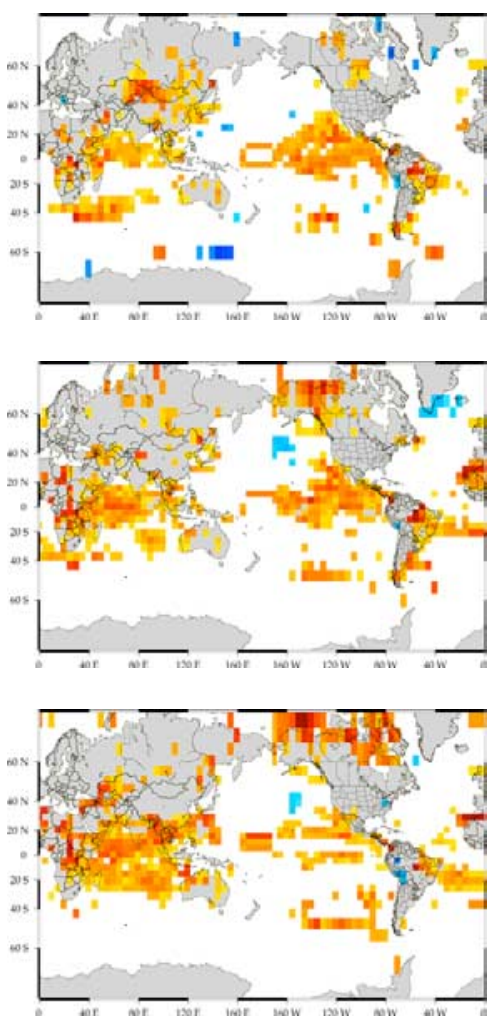

Thailand
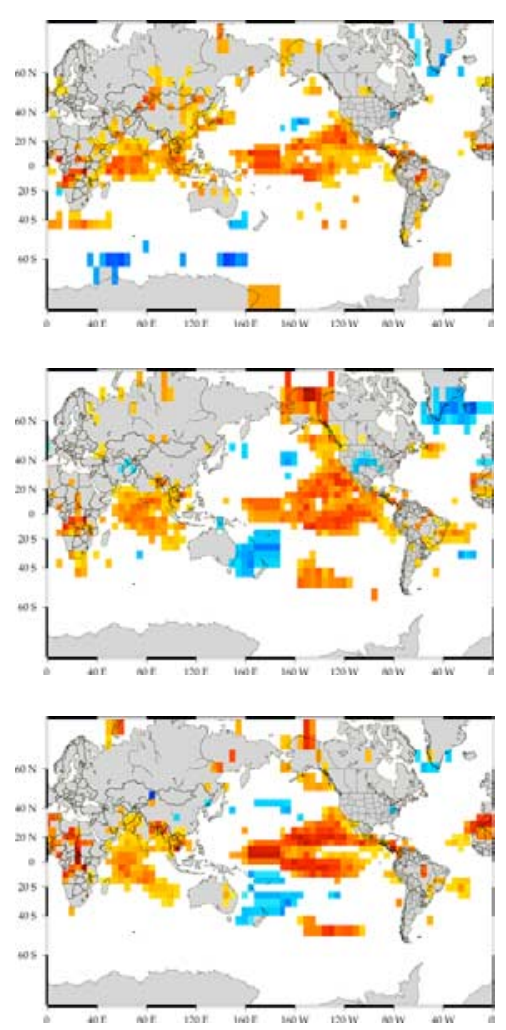

$0.4 \quad 0.5 \quad 0.6$

Figure 2. Pearson correlations between the Pinus chronologies and global surface temperature. Chronologies are listed in the columns ((left) Bhutan, (middle) India, and (right) Thailand) and seasonal time periods are shown in the rows ((top) DJF, (middle) MAM, and (bottom) JJAS).

monsoon rainfall (ISMR) the following summer. Dash et al. [2005] show that winter (DJF) temperature north of $45^{\circ} \mathrm{N}$ is inversely related to snow depth, such that warmer (colder) winters result in lower (higher) snow depth, which leads to increased (decreased) activity in ISMR. Therefore the positive correlations for Bhutan pines with surface temperature over parts of high-latitude Asia are consistent with these findings, indicating that high temperatures in Asia lead to low snow cover, and an increase in summer monsoon rainfall that is beneficial to growth for these mountain pines.

\subsection{North Pacific Ocean}

[12] Strong correlations are seen for the Bhutan pines with the North Pacific Ocean and the Gulf of Alaska, with a pattern of positive correlations extending well inland in northwestern North America. This same pattern is weakly expressed in the Thai and Indian chronologies. This north Pacific pattern is suggestive of the Pacific Decadal Oscillation (PDO), which is a long-lived El Nino like pattern of Pacific climate variability [Mantua et al., 1997].

\section{Discussion}

[13] Our pine chronologies show correlation patterns with SST and terrestrial surface temperature that reflect the influence of the tropical oceans in controlling the moisture availability in these wet/dry tropical to subtropical sites. It also reveals links to Asian land temperature and the north Pacific during the pre-monsoon period. Such tropical-extra tropical climate links have been suggested by Deser et al. [2004] and D'Arrigo et al. [2005] and illustrate a direction for further research.

[14] The pine sites range from 1,000 to 3,000 meters. Consequently, correlations are often ambiguous with local station data that are typically from much lower sites. In the case of SLM, Buckley et al. [1995] and D'Arrigo et al. [1997] note difficulty in calibrating to local data, in spite of strong common signal in the chronology indices. Buckley et al. [1995] found the strongest correlation with transition season rainfall preceding the monsoon (Apr-May), suggesting that the duration of the monsoon is more important to growth than rainfall intensity during peak months. Analyses of elevational temperature/rainfall/relative humidity profiles from north Thailand by Komonjinda [2003] illustrate how poorly low-elevation stations reflect mountain climate. Correlations with global surface temperature as shown in this paper can be explained by looking at the relationship between these regions, and we are encouraged by these results.

[15] Singhrattna et al. [2005a, 2005b] show that rainfall over central Thailand has become correlated with ENSO 
since the 1980s, following decades of weak correlation. Krishna Kumar et al. [1999] show the opposite situation in India, with ISMR significantly correlated with ENSO for the early half of the 20th Century, followed by a loss of correlation in the post-1980s period. This implies a shift in the centers of influence of ENSO from India to Thailand during this time, and helps to explain the difference in trend between the two chronologies as seen in Figure 1, in spite of their similar correlation fields. Singhrattna et al. [2005b] also describe correlation between central Thailand rainfall and pre-monsoon (Mar-May) land surface temperatures representing the land-ocean thermal gradient, and this is consistent with the findings in this paper. Further expansion of the pine network across a broader region of Southeast Asia might shed light on the shifting centers of influence of ENSO, and the timing of any such shifts.

[16] It is encouraging to see links between these chronologies and known regions of influence on the Asian monsoon. The results lead the way toward using an expanded pine network to analyze past variability in climate, with respect to large-scale features related to monsoon and ENSO. Variable strength in the monsoon on timescales of decades to centuries can only be analyzed by extending instrumental records with proxies like tree rings. This study shows the possibility of doing so for tropical and subtropical Asia using Pinus species, though a dearth of detailed physiological information needs to be addressed. We are engaged in expanding the pine network across Southeast Asia in Laos, Myanmar and the Philippines. More comprehensive analyses are needed on an expanded network to look at monsoon influence on varying temporal and spatial scales.

[17] Acknowledgments. We thank the U.S. National Science Foundation and the National Oceanic and Atmospheric Administration for funding this research, as well as the many colleagues in Bhutan, India and Thailand who have helped so much. Special thanks to M. Barbetti from Sydney University in Australia and Manas Watanasak from Mahidol University in Thailand for assistance with the SLM chronology, and to Paul Krusic of the Lamont-Doherty Earth Observatory, for his tireless efforts in Bhutan. We also wish to thank 3 anonymous reviewers whose criticisms and suggestions vastly improved this paper. Lamont-Doherty contribution 6826 .

\section{References}

Borgaonkar, H. P., G. B. Pant, and K. Rupa Kumar (1999), Tree-ring chronologies from western Himalaya and their dendroclimatic potential, IAWA J., 20, 295-309.

Buckley, B. M., M. Barbetti, M. Watanasak, R. D. D'Arrigo, S. Boonchirdchoo, and S. Sarutanon (1995), Dendrochronological investigations in Thailand, IAWA J., 16, 393-409.

Cook, E. R., and K. Peters (1997), Calculating unbiased tree-ring indices for the study of climate and environmental change, Holocene, 7, 361370 .

D’Arrigo, R. D., G. C. Jacoby, and P. J. Krusic (1994), Progress in dendroclimatic studies in Indonesia, Terr. Atmos. Oceanic Sci., 5, 349-363.

D’Arrigo, R. D., M. Barbetti, M. Watanasak, B. M. Buckley, P. Krusic, S. Boonchirdchoo, and S. Sarutanon (1997), Progress in dendroclimatic studies of mountain pine in northern Thailand, IAWA J., 18, $433-444$.

D’Arrigo, R. D., R. Wilson, C. Deser, G. Wiles, E. Cook, R. Villalba, A. Tudhope, J. Cole, and B. Linsley (2005), Tropical-North Pacific climate linkages over the past four centuries, J. Clim., in press.

Dash, S. K., G. P. Singh, M. S. Shekhar, and A. D. Vernekar (2005), Response of the Indian summer monsoon circulation and rainfall to seasonal snow depth anomaly over Eurasia, Clim. Dyn., 24, 1-10.

Deser, C., A. Phillips, and J. Hurrel (2004), Pacific interdecadal climate variability: Linkages between the tropics and North Pacific during boreal winter since 1900, J. Clim., 17, 3109-3124.
Dickson, R. R. (1984), Eurasian snow cover versus Indian monsoon rainfall-An extension of the Hahn-Shukla results, J. Clim. Appl. Meteorol., 23, $171-173$.

Eriksson, M. (1989), Integrating forest growth and dendrochronological methodologies, Ph.D. diss., Univ. of Minn., Twin Cities.

Fritts, H. C. (1976), Tree Rings and Climate, 567 pp., Elsevier, New York. Gautier, C., P. Peterson, and C. Jones (1998), Variability of air-sea interactions over the Indian Ocean derived from satellite observations, J. Clim., $11,1859-1873$.

Hahn, D. J., and J. Shukla (1976), An apparent relation between Eurasian snow cover and Indian monsoon rainfall, J. Atmos. Sci., 33, 2461-2462.

Jacoby, G. C. (1989), Overview of tree-ring analysis in tropical regions, in Growth Rings in Tropical Woods, edited by P. Bass and R. E. Vetter, IAWA Bull., 10, 99-108.

Jones, P. D., T. J. Osborn, K. R. Briffa, C. K. Folland, E. B. Horton, L. V. Alexander, D. E. Parker, and N. A. Rayner (2001), Adjusting for sampling density in grid box land and ocean surface temperature time series, J. Geophys. Res., 106, 3371-3380.

Komonjinda, S. (2003), An analysis of rainfall, temperature and relative humidity in north Thailand: Application to paleoclimatology, M.A. thesis, Fac. of Environ. and Resour. Stud., Mahidol Univ., Salaya, Thailand.

Krishna Kumar, K., B. Rajagopalan, and M. A. Cane (1999), On the weakening relationship between Indian monsoon and ENSO, Science, 284, $2156-2159$

Mantua, N. J., S. R. Hare, Y. Zhang, J. M. Wallace, and R. C. Francis (1997), A Pacific decadal climate oscillation with impacts on salmon, Bull. Am. Meteorol. Soc., 78, 1069-1079.

Meehl, G. A., and J. M. Arblaster (2003), Mechanisms for projected future changes in south Asian monsoon precipitation, Clim. Dyn., 21, 659-675.

Mohanty, U. C., K. J. Ramesh, and M. C. Pant (1996), Certain seasonal characteristic features of oceanic heat budget components over the Indian Seas in relation to the summer monsoon activity over India, Int. J. Climatol., 16, 243-264.

Osborn, T. J., K. B. Briffa, and P. D. Jones (1997), Adjusting variance for sample size in tree-ring chronologies and other regional mean timeseries, Dendrochronologia, 15, 89-99.

Pumijumnong, N., D. Eckstein, and U. Sass (1995), Tree-ring research on Tectona grandis in northern Thailand, IAWA J., 16, 385-392.

Rao, K. G., and B. N. Goswamy (1988), Interannual variations of the SST over the Arabian Sea and the Indian monsoon: A new perspective, Mon. Weather Rev., 116, 558-568.

Sankar-Rao, M., M. K. Lau, and S. Yang (1996), On the relationship between Eurasian snow cover and the Asian summer monsoon, Int. J. Climatol., 16, 605-616.

Singhrattna, N., B. Rajagopalan, K. Krishna Kumar, and M. Clark (2005a), Interannual and interdecadal variability of Thailand summer monsoon, J. Clim., 18, 1697-1708.

Singhrattna, N., B. Rajagopalan, M. Clark, and K. Krishna Kumar (2005b), Seasonal forecasting of Thailand summer monsoon rainfall, Int. J. Climatol., 25, 649-664.

Stokes, M. A., and T. L. Smiley (1968), An Introduction to Tree-Ring Dating, 73 pp., Univ. of Chicago Press, Chicago, Ill.

Thompson, L. G. (2001), Stable isotopes and their relationship to temperature as recorded in low latitude ice cores, in Geological Perspectives of Global Climate Change, edited by L. C. Gerhard, W. E. Harrison, and B. M. Hanson, pp. 99-120, Am. Assoc. of Petrol. Geol., Tulsa, Okla. Urban, F. E., J. E. Cole, and J. T. Overpeck (2000), Influence of mean climate change on climate variability from a 155-year tropical Pacific coral record, Nature, 407, 989-993.

Wigley, T. M. L., K. R. Briffa, and P. D. Jones (1984), On the average of correlated time series, with applications in dendroclimatology and hydrometeorology, J. Clim. Appl. Meteorol., 23, 201-213.

Worbes, M. (1995), How to measure growth dynamics in tropical trees-A review, IAWA J., 16, 337-352.

Yadav, R. R., W. K. Park, and A. Bhattacharyya (1997), Dendroclimatic reconstruction of April-May temperature fluctuations in the western Himalaya of India since A, D. 1698, Quat. Res., 48, 187-191.

A. Bhattacharyya, Birbal Sahni Institute of Palaeobotany, 53, University Road, Lucknow 226 007, India.

B. M. Buckley, Tree Ring Laboratory, Lamont-Doherty Earth Observatory, Palisades, NY 10964, USA. (bmb@1deo.columbia.edu)

V. Chaudhary, Seismology Division, Department of Science and Technology, Technology Bhavan, New Mehrauli Road, New Delhi 110 06, India.

B. I. Cook, Department of Environmental Science, University of Virginia, PO Box 400123, Charlottesville, VA 22904, USA.

D. Dukpa, Tree-Ring Lab, RNR-RC, Jakar, Bhutan. 